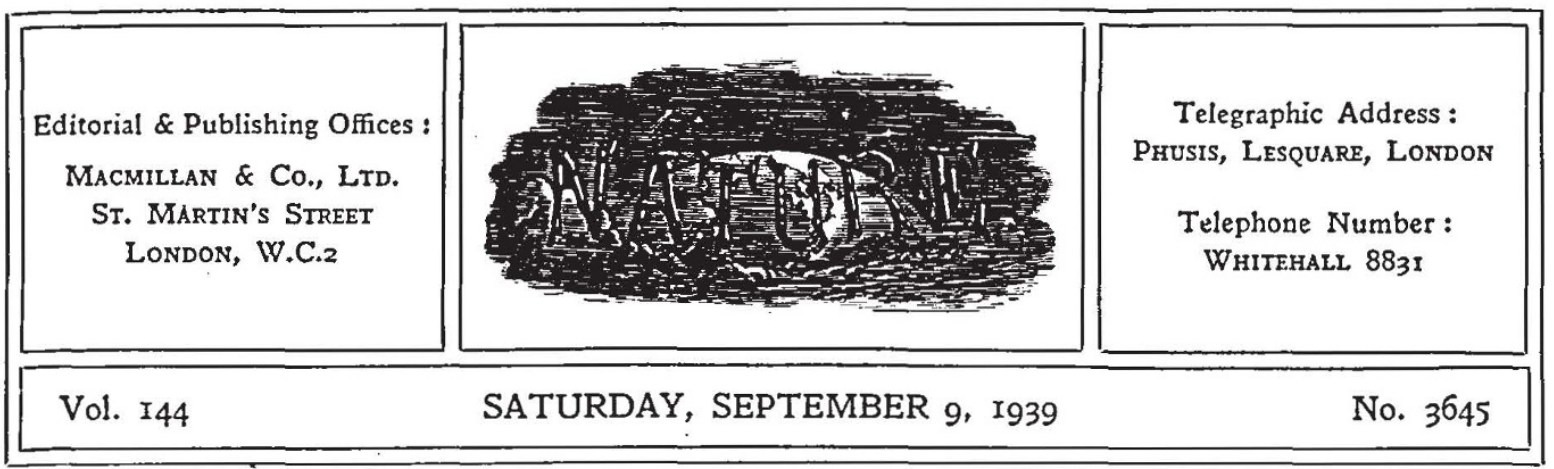

\title{
THE VOICE OF SCIENCE
}

$\mathrm{O}^{\mathrm{s}}$ TCE more the burden of war is laid upon us. Once more, as in 1914, the cynical disregard of Germany for the rights of small nations has constrained the British people to take up arms in the cause of justice and fair dealing in international relations. The challenge of the German Reich has been accepted reluctantly, and with no illusions as to the nature of the glories of modern warfare, only after every effort to secure a peaceful but equitable settlement of the differences between Germany and Poland has failed. It has been accepted with full realization of the gravity of every implication of the decision. But in turning to war as the last resort, the British people has acted with a unanimity such as never before in its history, and with a grim determination that no effort shall be spared in the endeavour to ensure that the cause which it holds just shall prevail.

From 1914-18, the Allies opposed dynastic ambitions in the interests of the freedom of peoples. No longer were the people to be the pawns of the political intrigues of their rulers. The world, it was said, was to be made safe for democracy-words that now have a mocking ring. In 1939, the canker has sunk deeper. It is not merely political liberty that is at stake, though that too is jeopardized. It is the spirit of man.

In no previous war has science played so great a part as that which will be demanded of it in the struggle that is at hand. For a time, while the issue hangs in the balance, it is the duty of the man of science to lay aside his just misgivings whether the greatest force of the human intellect should thus be harnessed to the forces of destruction. For the moment, the interests of pure science as an intellectual pursuit and discipline must remain in abeyance. The energies, the abilities, and the knowledge of each and every individual with scientific training must be directed without remission to the service of the Allied cause. Nevertheless, the end to be attained, and the end which science should hold ceaselessly before the eyes of the Allied peoples, is not destruction, but a constructive ideal-to ensure in the future such conditions as will make possible the advancement of all the peoples of the world without discrimination, according to the status and the traditions of each, in the light shed by reason and scientific knowledge. To keep alive the aims of science in furthering the pursuit of truth in the universe and the relation of that truth to the developments of man's nature, without regard to tribal and racial dis. tinctions, should be, indeed, must be, the ultimate function of the scientific thinker, whatever may be his more immediate preoccupations.

As to the form in which that ideal will find embodiment, at the moment, in the turmoil of initial operations, it is too soon to attempt a forecast; but that it is no idealist's dream is certain. The failure of the League of Nations as a political organization has cast discredit in the popular mind on such forms of international co-operation. Possibly the League of Nations came before its time, and this has obscured in the popular verdict the enormous value of its scientific work in the study of social and economic problems, and the progress which has followed, where the practical application of the solutions suggested has not conflicted with the trends of nationalist development. To extend the fields in which such co-operation between peoples may be applied is the task of the future, when the time comes, as it surely will, for reconstruction. 